Bangladesh J Med M icrobiol 2017; 11 (01): 23-25

Bangladesh Society of Medical Microbiologists

Review Article

\title{
Zika virus- Its control and prevention
}

\author{
UmmeShahera ${ }^{1}$ \\ ${ }^{1}$ Department of Virology, Bangabandhu Sheikh Mujib Medical University
}

\section{Introduction:}

Zika virus is a flavivinus, in the family Flaviviridae Its name comes from the Zika forest Uganda, where the virus was first isolated in $1947 .{ }^{1}$ Since the 1950s, it has been known to occur within a narrow equatorial belt from Africa to Asia. From 2007 to 2016, the virus spread eastward, across the Pacific Ocean to the Americas, where in 2015-16 Zika virus epidemic reached pandemic levels. ${ }^{2}$ In February 2016, WHO declared a Public Heal th Emergency of International Concem as evidence grew that Zika can cause birth defects as well as neurological problems. ${ }^{1,2}$ The virus can be transmitted from an infected pregnant woman to her fetus, causesmicrocephaly and other severe brain anomalies in the infant. ${ }^{3-5}$ Zika infections in adults can result in Guillain-Barré syndrome 5 Prior to this outbreak, Zika infection was considered to be a mild infection, as most Zika virus infections are asymptomatic, making it difficult to determine precise estimates of the number of cases. ${ }^{6}$ In approximately one in five cases, Zika virus infections result in Zika fever, a minor illness that causes symptoms such as fever and a rash. On 9 March 2016, WHO announced that research should priorities prevention and diagnosis, novel mosquito control measures, and diagnostic tests that can detect dengue and chikungunya as well as Zika. ${ }^{7}$

\section{Treatment, Prevention, and Control}

As no Zika virus vaccine exists; thus, prevention and control measures center on avoiding mosquito bites, reducing sexual transmission, and controlling the mosquito vector. Potentially effective methods of prevention that are focused

\footnotetext{
Correspondence:

Dr. Umme Shahera

Department of Virology

Bangabandhu Sheikh Mujib Medical University

Phone: 01711345008
}

on reducing infections among pregnant women include avoiding unnecessary travel to areas of ongoing Zika virus transmission, avoiding unprotected sexual contact with partners who are at risk for Zika virus infection. ${ }^{8}$ Travellers and those living in affected areas should take the basic precautions to protect themselves from mosquito bites byusing mosquito repellent, permethrin treatment for clothing, ${ }^{9}$ bed nets, ${ }^{10}$ window screens, ${ }^{11,12}$ and air conditioning. ${ }^{13,14}$

\section{M osquito bites}

Protection against mosquito bites is a key measure to prevent Zika virus infection. This can be done by wearing clothes (preferably light-coloured) that cover as much of the body as possible; using physical barriers such as window screens or closing doors and windows; sleeping under mosquito nets; and using insect repellent containing DEET, IR3535 or icaridin according to the product label instructions. Special attention and help should be given to those who may not be able to protect themselves adequately, such as young children, thesick or elderly.

\section{Vector control:}

The most effective A. aegypti vector control relies on an integrated approach that involves elimination of $A$. aegypti mosquito breeding sites, application of larvicides, and application of insecticides to kill adult mosquitoes. However, each of these approaches has substantial limitations. Communities are often mobilized to reduce $A$. aegypti breeding sites, but this strategy often fails, in part becauseof the presence of cryptic breeding sites in modern urban settings. ${ }^{15,16}$ The application of larvicides ${ }^{17}$ and indoor residual spraying ${ }^{17,18}$ have been effective in some settings. Given these limitations, an integrated prevention and vectorcontrol approach combined with timely detection of illness and development of a rapid response that involves the community are recommended. ${ }^{19}$ 


\section{M easures should be taken to control Sexual transmission:}

Sexual transmission of Zika virus has been documented in several different countries. To reduce the risk of sexual transmission and potential pregnancy complications the sexual partners of pregnant women, living in or returning from areas where local transmission of Zika virus occurs should practice safer sex (including using condoms) or abstain from sexual activity throughout the pregnancy.

People living in areas where local transmission of Zika virus occurs should also practice safer sex or abstain from sexual activity. In addition, people retuming from areas where local transmission of Zika virus occurs should adopt safer sexual practices or abstain from sex for at least 8 weeks after their retum, even if they don't have symptoms. If men experience Zika virus symptoms they should adopt safer sexual practices or consider abstinence for at least 6 months. Those planning a pregnancy should wait at least 8 weeks before trying to conceive if no symptoms of Zika virus infection appear, or 6 months if one or both members of the coupleare symptomatic.

As of April 2016, Zika has been documented by sexual transmission in six countries - Argentina, Chile, France, Italy, New Zealand and the United States - during the 2015 outbreak. ${ }^{20}$ So, Zika can be transmitted from a man to his sex partners. In 2014, Zika virus was found in the semen of a man at least two weeks after Zika infection.21,22 In early February 2016, the Dallas County Health and Human Services department reported that a man from Texas who had not travelled abroad had been infected after his male monogamous sexual partner had anal penetrative sex with him one day before the onset of symptoms. ${ }^{21,23,24}$ As of February 2016, fourteen additional cases of possible sexual transmission have been under investigation, but it remained unknown whether women can transmit Zika to their sexual partners. ${ }^{25}$ As of J uly 2016, there has been at least one case of a woman transmitting Zika to her sexual partner. ${ }^{26}$

Couples with men who traveled to an area with Zika, but did not develop symptoms of Zika, should consider using condoms or not having sex for at least 8 weeks after their return in order to minimize risk. Couples with men who live in an area with Zika, but have not developed symptoms, might consider using condoms or not having sex while there is active Zika transmission in the area. ${ }^{27}$ In March 2016, CDC updated its recommendations about length of precautions for couples, and advised that heterosexual couples with men who have confirmed Zika fever or symptoms of Zika should consider using condoms or not having penetrative sex (i.e, vaginal intercourse, anal intercourse, or fellatio) for at least 6 months after symptoms begin. This includes men who live in and men who traveled to-areas with Zika. Several countries have taken the unusual step of advising their citizens to delay pregnancy until more is known about the virus and its impact on fetal development ${ }^{28}$

\section{Conclusion:}

Outbreaks of Zika virus infection, caused by an emerging mosquito-bome flavivirus, have occurred in Africa, Southeast Asia, and the Pacific Islands; currently, there is an ongoing Zika virus outbreak in the Americas. Zika virus is transmitted to humans via the bite of an infected Aedes mosquito.The underlying reasons for the emergence of Zika virus in the past decade are unknown. Recent global increases in the incidence and spread of dengue, chikungunya, and now Zika virus - all with $A$. aegypti as the primary vector - suggest common underlying mechanisms for their emergence, such as globalization and urbanization. Other possible explanations include viral mutations affecting transmission or virulence and viral introduction to previously unexposed populations leading to epi demic spread. There is no specific treatment for Zika virus infection and there is no vaccine for prevention. Management consists of symptomatic treatment. Preventive measures include personal protective measures to prevent mosquito bites and institution of measures to eliminate and control mosquito breeding sites.Sexual transmission of Zika virus has been described. It is prudent for individuals with Zika virus infection/exposure to abstain from sexual activity (vaginal, anal, and oral sex) or use barrier protection; men or women who have a pregnant partner should follow such guidance for the duration of the pregnancy.

As Zika virus is a serious life threatening condition, people should be alert about its consequences. So, a good and ideal preventive measures will be hel pful to eradicate this emerging viral disease from the world.

\section{REFERENCES:}

1. Sikka, Veronica; Chattu, Vijay Kumar; Popli, Raaj K.; et al."The emergence of zika virus as a global health security threat: A review and a consensus statement of the INDUSEM J oint working Group (JWG)". J oumal of Global Infectious Diseases 2016;8 (1): 3-15.

2. Chastain, Mary. "National Institutes of Heal th: Zika Virus Is a 'Pandemic"'. Breitbart. 2016.

3. Rasmussen, Sonja A.; Jamieson, Denise J.; Honein, Margaret A.; Petersen, Lyle R. "Zika Virus and Birth Defects - Reviewing the Evidence for Causality". New England J ournal of Medicine 2016;374 (20). 
4. "CDC Concludes Zika Causes Microcephaly and Other Birth Defects". CDC. 13April 2016.

5. "Zika Virus Microcephaly And Guillain-Barré Syndrome Situation Report" (PDF). World Health Organization. 7 A pril 2016.

6. "Brazil Health Minister: Zika epidemic worse than thought". ITV News. 28J anuary 2016.

7. "WHO and experts prioritize vaccines, diagnostics and innovative vector control tools for Zika R\&D". WHO. 9 March 2016.

8. Update: interim guidelines for health care providers caring for pregnant women and women of reproductive age with possible Zika virus exposure - United States, 2016. MMWR Morb Mortal Wkly Rep 2016;65:122-127

9. Banks SD, Murray N, Wilder-Smith A, Logan JG. Insecticide treated clothes for the control of vector-borne diseases: a review on effectiveness and safety. Med Vet Entomol 2014; 28:Suppl 1:14-25

10. Lenhart A, Orelus N, Maskill R, Alexander N, Streit T, McCall PJ. Insecticide-treated bednets to control dengue vectors: preliminary evidence from a controlled trial in Haiti. Trop Med Int Heal th 2008; 13:56-67

11. Manrique-Saide $P$, Che-Mendoza $A$, Barrera-Perez $M$, et al. Use of insecticidetreated house screens to reduce infestations of dengue virus vectors, Mexico. Emerg Infect Dis 2015;21:308-311

12. Che-Mendoza A, Guillermo-May G, Herrera-Bojórquez $J$, et al. Long-lasting insecticide-treated house screens and targeted treatment of productive breeding-sites for dengue vector control in Acapulco, Mexico. Trans R Soc Trop Med Hyg 2015; 109:106-115

13. Brunkard JM, Robles López JL, Ramirez J, et al. Dengue fever seroprevalence and risk factors, Texas-Mexico border, 2004. Emerg Infect Dis 2007;13:1477-1483

14. Reiter $P$, Lathrop $S$, Bunning $M$, et al. Texas lifestyle limits transmission of dengue virus. Emerg Infect Dis 2003;9:86-89

15. Heintze C, Velasco Garrido M, Kroeger A. What do community-based dengue control programmes achieve? A systematic review of published evaluations. Trans $\mathrm{R}$ Soc Trop Med Hyg 2007;101:317-325

16. Barrera R, Amador M, Diaz A, Smith J, Munoz-J ordan $J \mathrm{~L}$, Rosario Y. Unusual productivity of Aedes aegypti in septic tanks and its implications for dengue control. Med Vet Entomol 2008;22:62-69
17. Vazquez-Prokopec GM, Kitron U, Montgomery B, Horne P, Ritchie SA. Quantifying the spatial dimension of dengue virus epidemic spread within a tropical urban environment PLoS Negl Trop Dis 2010;4:e920-e920

18. Paredes-Esquivel $C$, Lenhart $A$, Del Río $R$, et al. The impact of indoor residual spraying of deltamethrin on dengue vector populations in the Peruvian Amazon. Acta Trop 2016; 154:139-144

19. Adalja AA, Sell TK, Bouri N, Franco C. Lessons learned during dengue outbreaks in the United States, 2001-2011. Emerg I nfect Dis 2012; 18:608-614

20. "Zika Virus Microcephaly And Guillain-Barré Syndrome Situation Report" (PDF). World Health Organization. 7 A pril 2016. Retrieved 8A pril 2016.

21. Oster, Alexandra M.; Brooks, J ohn T.; Stryker, J o Ellen; et al."Interim Guidelines for Prevention of Sexual Transmission of Zika Virus". Morbidity and Mortality Weekly Repor 2016; t 65 (5): 120-121.

22. Musso, Didier; Roche, Claudine; Robin, Emilie; Nhan, Tuxuan; Teissier, Anita; Cao-Lormeau, Van-Mai. "Potential Sexual Transmission of Zika Virus". Emerging Infectious Diseases 2015;21(2):359-361.

23. "DCHHS Reports First Zika Virus Case in Dallas County Acquired Through Sexual Transmission" (PDF). Dallas County Health and Human Services. 2 February 2016.

24. "Male-to-Male Sexual Transmission of Zika Virus Texas, January 2016". CDC Weekly 2016; (14): 372-4.

25. "CDC encourages following guidance to prevent sexual transmission of Zika virus". CDC Newsroom Releases. Centers for Disease Control and Prevention. 23 February 2016.

26. "WHO chief going to the Olympics, says Zika risk low". www.msn.com 2016-07-30.

27. Petersen, Emily E.; Polen, Kara N.D.; Meaney-Delman, Dana; et al. "Update: Interim Guidance for Health Care Providers Caring for Women of Reproductive Age with Possible Zika Virus Exposure - United States, 2016". MMWR. Morbidity and Mortality Weekly Report 65 (12).

28. "Zika virus triggers pregnancy delay calls". BBC. 23 January 2016. 